\title{
Symptom Severity, Self-efficacy and Treatment-Seeking for Mental Health Among US Iraq/Afghanistan Military Veterans
}

\author{
Mary Keeling ${ }^{1}\left(\right.$ Nicholas $^{\text {Barr }}{ }^{2} \cdot$ Hazel Atuel $^{2} \cdot$ Carl A. Castro $^{2}$
}

Received: 4 June 2018 / Accepted: 11 February 2020 / Published online: 17 February 2020

(C) The Author(s) 2020

\begin{abstract}
Military veterans have high rates of mental health problems, yet the majority do not seek treatment. Understanding treatmentseeking in this population is important. This study investigated if symptom severity and self-efficacy are associated with treatment-seeking among US Iraq/Afghanistan veterans. Survey data from 525 veterans meeting clinical criteria for PTSD and depression were included of which, 54.4\% had sought treatment in the past 12 months. Multivariate logistic regression analysis indicated that high symptom severity was associated with treatment seeking, whereas high self-efficacy was associated with a decreased likelihood to seek treatment. Self-efficacy could be an underlying mechanism of treatment seeking decisions.
\end{abstract}

Keywords Treatment-seeking $\cdot$ Health belief model $\cdot$ Symptom severity $\cdot$ Self-efficacy $\cdot$ Military veterans

Evidence indicates that military personnel and veterans experience mental health conditions at elevated rates (Hoge et al. 2004; Seal et al. 2009; Thomas et al. 2010). For example, Seal et al. (2009), found in their study with 289,328 Iraq and Afghanistan veterans entering Veterans Affairs (VA) health care from 2002 to 2008 , that mental health diagnoses increased substantially after the start of the Iraq war, especially among veterans younger than 25 years old. Yet, consistent with the general population, the prevalence of treatment-seeking for mental health problems is between 23

Mary Keeling

mary.keeling@uwe.ac.uk

Nicholas Barr

nicholas.barr@unlv.edu

Hazel Atuel

atuel@usc.edu

Carl A. Castro

cascastro@usc.edu

1 Department of Health and Social Sciences, Faculty of Health and Applied Sciences, University of the West of England, Frenchey Campus, Coldharbour Road, Bristol BS16 1QY, UK

2 Center for Innovation and Research on Veterans \& Military Families, USC Suzanne Dworak-Peck School of Social Work, University of Southern California, 1150 South Olive Street, Suite 1400, Los Angeles, CA 90015, USA and 58 percent (Clement et al. 2014; Henderson et al. 2013; Ouimette et al. 2011; Porcari et al. 2017; Rosen et al. 2011; Stecker et al. 2007). Considering that, for the most part, both military personnel and veterans have access to a universal healthcare system, understanding what might increase or decrease the propensity to seek treatment for mental health problems among military veterans is an important area of investigation.

The Health Belief Model (HBM) (Rosenstock et al. 1988) attempts to explain health behaviors such as treatmentseeking and states that health related action depends on the simultaneous occurrence of three factors: 1 . Sufficient health concern to make the health concern salient or relevant, such as experiencing severe symptoms. 2. Threat perception, which is the belief that one is susceptible or vulnerable to a serious health problem, such as impaired functioning. 3 . The belief that engaging in an adaptive health behavior, such as seeking treatment, would be beneficial in reducing the threat, minus perceived costs and barriers, such as the cost/barrier of experiencing stigma.

An additional factor of the HBM is self-efficacy. Selfefficacy is an individual's belief in his or her capacity to execute behaviors necessary to produce specific performance attainments and reflects an individual's confidence in their ability to exert control over their motivation, behavior, and social environment (Bandura 1982). Rosenstock et al. (1988) proposed that to understand 
health behavior related to conditions requiring long term changes, such as accessing mental health care, consideration of the confidence individuals have in their ability to engage in such health behavior plays a role. As well as the simultaneous occurrence of the three factors described, individuals must also feel competent and confident (selfefficacious) to implement that change (Rosenstock et al. 1988).

Evidence for the first two factors of HBM are established in the literature investigating treatment-seeking for mental health among veterans. Symptom severity and greater impairment are consistently reported to be associated with seeking treatment for mental health problems among OIF/OEF veterans (DeViva et al. 2016; Hines et al. 2014; Porcari et al. 2017; Rosen et al. 2011). Evidence for the cost/benefit factor related to stigma and treatmentseeking described by the HBM has however, received inconsistent support, possibly due to methodological challenges (Sharp et al. 2015). Evidence for the role of selfefficacy in seeking treatment among military and veteran populations has not been examined.

Evidence for the role of self-efficacy in treatmentseeking from other populations is limited and inconsistent. Inverse to the predictions made by Rosenbeck et al. (1988), Jackson et al. (2007) found that lower self-efficacy was associated with a higher likelihood to seek treatment among a rural general population sample. However, a Swedish study found no association between general selfefficacy and treatment-seeking, but did find that lower selfefficacy was associated with being more likely to report barriers to care including, "it will pass by itself" and "I did not know where to get treatment" (Andersson et al. 2014).

Based on the limited investigation of the role of selfefficacy in veteran populations, the inconsistent results from other populations and, the proposed important role self-efficacy may play in decisions to seek treatment, investigation of self-efficacy and treatment seeking could prove fruitful for improving understanding of veterans' treatment-seeking decisions. Moreover, self-efficacy presents a possible target of interventions designed to improve treatment seeking since it is a cognitive factor which is amenable to change (Andersson et al. 2014; Rosenstock et al. 1988). The current study therefore investigated the role of self-efficacy in decisions to seek treatment among a US veteran sample. Based on the HBM, this study will test two hypotheses:

H1 Higher symptom severity will be associated with an increased likelihood to seek treatment.

H2 Higher self-efficacy will be associated with an increased likelihood to seek treatment.
Whether the interaction between self-efficacy and symptom severity increases the likelihood to seek treatment will also be explored.

Finding a main effect of symptom severity on treatmentseeking will provide additional support for existing evidence and for an important factor of the HBM. If a main effect of self-efficacy on treatment-seeking is found this will support Rosenbeck et al.'s (1988) proposal to include self-efficacy in the HBM. Moreover, it would show that self-efficacy is a cognitive mechanism important in the treatment-seeking decisions of veterans. Investigating both hypotheses will help inform interventions aimed at increasing the propensity to seek treatment for mental health issues among military veterans.

\section{Method}

\section{Sample and Recruitment}

Veterans who had previously participated in veteran survey studies in Los Angeles County, Orange County, Chicago, and the San Francisco Bay area and had agreed to be recontacted about future research participation opportunities were invited, via email, to participate in the current study $(n=2280)$. Eligibility criteria for participation included, having served since the terrorist attacks of September 11, 2001 (Post 9/11 veterans), and to have left military service (not currently be active duty).

\section{Data Collection Procedures}

Invitations to participate were sent to the 2280 veterans via MailChimp. The email consisted of an invitation to participate, study information sheet, and a link to the online survey. The online survey was constructed in Qualtrics and all data was collected via this online platform. The beginning of the survey included eligibility questions which if not met the survey was terminated. A consent form followed, which had to be completed before the survey would continue. On completion of the survey, participants were redirected to an additional Qualtrics survey where they could provide their name and email address to receive a $\$ 15$ gift card as compensation for their time. The contact information for the gift card was collected separately to ensure study data remained anonymous. Gift cards were emailed to those who completed the survey and provided their information. Their contact information was subsequently removed from the mailing list to ensure they were not contacted further to participate.

Participant recruitment lasted for 10 months, May 2016 to February 2017. The MailChimp invite was resent to all veterans who had not already provided information to receive the gift card, approximately twice a month. Some veterans 
contacted the research team to inform them that they were not eligible to take part. Their contact information was removed to avoid further contact.

\section{Measures}

\section{Demographics}

Age, gender, marital status, employment status, education, type of military discharge, and eligibility to receive VA benefits and services.

\section{Posttraumatic Stress Disorder}

PTSD was measured using the Posttraumatic Stress Disorder Checklist for DSM-5 (PCL-5) (Weathers et al. 2013). The PCL-5 is a 20 item self-report measure assessing the 20 DSM-5 symptoms of PTSD. The PCL-5 demonstrates strong internal consistency (Cronbach's $\alpha=0.96$ ), test-retest reliability $(\mathrm{r}=0.84)$, and convergent and discriminant validity with a US veteran population (Bovin et al. 2016). Within this study sample strong internal consistency was also found (Cronbach's $\alpha=0.96$ ). Symptom severity score is obtained by summing the scores for each of the 20 items (range $0-80$ ). A PCL-5 cut point score of 33 is the clinical cutoff for this scale.

\section{Depression}

Depression was measured using the Patient Health Questionnaire 9 (Kroenke et al. 2001), a 9-item measure on a 4-point Likert type scale. Scores on the PHQ-9 range from 0 to 27 with a clinical cut point score of 10 or above. The PHQ-9 has strong internal consistency (Cronbach's $\alpha=0.89$ ) and test-retest reliability $(r=0.84)$ (Kroenke et al. 2001). Within this study sample a similar internal consistency is found (Cronbach's $\alpha=0.88$ ).

\section{General Self-efficacy}

Self-efficacy was measured using the General Self-Efficacy Scale which is a 10 item scale. Participants are asked to rate on a four-point Likert scale, ranging from "not at all true" to "exactly true", how true ten statements are, for example "I can always manage to solve difficult problems if I try hard enough". The scale was created to assess the general sense of perceived self-efficacy a person has of themselves. The scale has good internal consistency (Cronbach's $\alpha=0.86$ ) (Schwarzer and Jerusalem 1995). Within this study's sample good internal consistency was also found (Cronbach's $\alpha=0.91)$.

\section{Treatment-Seeking}

Treatment-seeking was measured by asking the question: "Have you sought treatment for a mental, emotional, or stressful problem in the last year from a mental health professional (e.g. Psychiatrist, Psychologist, Social Worker, VA Clinician?)" with response options "yes" or "no".

\section{Statistical Analysis}

Since this study is interested in investigating treatmentseeking for mental health problems, only those who scored above the clinical cutoff for either PTSD or depression were included in the analysis. The predictor variable symptom severity was measured as depression severity (total score on the PHQ-9) and PTSD severity (total score on the PCL5). It is possible that severity of the different diagnoses effects treatment-seeking differently, therefore, the effect of depression symptom severity and PTSD symptom severity were investigated separately. Two samples were created; one including all participants who scored above the clinical cutoff on the PCL-5 only and one including all participants who scored above the clinical cutoff on the PHQ-9 only. The hypotheses were tested separately with each sample. Of note, 82 percent of the participants had co-morbid conditions and were included in both samples. All statistical analysis was conducted using SPSS Version 22.

To test both hypotheses, logistic regression analysis was conducted with treatment-seeking as the outcome variable. Initially each of the two predictors, symptom severity, measured as either PCL-5 score of PHQ-9 score, and general self-efficacy, were examined individually via univariate logistic regression analysis. Multivariate analysis logistic regression analysis with both predictors in the model was then conducted, followed by a multivariate analysis including demographic variables thought to be potentially associated with treatment-seeking based on a priori theory (age, gender, marital status). The covariates that were not significant in the model were removed after examining model fit. Interaction terms were included in the models as post hoc analyses to test for an interaction between symptom severity and self-efficacy.

\section{Ethics}

The study received approval from the (masked for review) Institutional Review Board and was considered exempt since study datum would be anonymous. This study was therefore performed in accordance with the ethical standards laid down in the 1964 Declaration of Helsinki and its later amendments. All participants provided informed consent prior to inclusion in the study and all data is anonymous. 


\section{Results}

The survey was completed by 576 veterans, with a response rate of $25.3 \%$. Whilst this response rate is low, it is likely due to the nature of the study focusing on mental health and treatment-seeking, therefore those with mental health experiences may have been more motivated to participate, compared to those who do not, as reflected in the high prevalence of PTSD and depression in the sample.

Of the 576 participants, 525 met the cut off for being a probable case for either PTSD and/or Depression. Only these 525 were included in the study. Demographic characteristics of the sample are shown in Table 1. Consistent with the profile of military veterans the majority were male, white, and educated to Bachelor's level. Only 5.5\% were not eligible to use VA services. As there was only one transgender veteran in the sample, and a priori theory indicates that gender is associated with treatment seeking, this participant was excluded from further analysis. Due to small numbers in the not VA eligible category, this variable was not included in further analysis. Of the 525 participants, 524 (99.8 percent) responded to the question asking if they had sought treatment for a mental, emotional, or stressful problem in the last year from a mental health professional, with 54.4 percent reporting they had sought treatment.
Table 1 Sample characteristics

\begin{tabular}{|c|c|c|c|}
\hline \multirow[t]{2}{*}{ Demographic } & \multirow[t]{2}{*}{ Total \% (n) } & \multicolumn{2}{|c|}{$\begin{array}{l}\text { Distribution of treatment seek- } \\
\text { ing } \%(\mathrm{n})\end{array}$} \\
\hline & & No & Yes \\
\hline Total & & $45.6(239)$ & $54.4(285)$ \\
\hline \multicolumn{4}{|l|}{ Age } \\
\hline Mean (SD) & $33.9(8.62)$ & 37.7 & 39.9 \\
\hline Range & $21-73$ & & \\
\hline \multicolumn{4}{|l|}{ Gender } \\
\hline Male & $79.4(417)$ & $48.1(200)$ & $51.9(216)$ \\
\hline Female & $20.4(107)$ & $36.4(39)$ & $63.6(68)$ \\
\hline Transgender & $0.2(1)$ & $0.0(0)$ & $100.0(1)$ \\
\hline \multicolumn{4}{|l|}{ Ethnicity } \\
\hline White & $48.6(255)$ & $38.2(97)$ & $61.8(157)$ \\
\hline Black or African American & $10.7(56)$ & $60.7(34)$ & $39.3(22)$ \\
\hline Hispanic/Latino & $26.1(137)$ & $52.6(72)$ & $47.4(65)$ \\
\hline Other & $14.7(77)$ & $46.8(269)$ & $54.4(285)$ \\
\hline \multicolumn{4}{|l|}{ Education } \\
\hline High school diploma or less & $12.6(66)$ & $15.2(10)$ & $84.8(56)$ \\
\hline Some college & $20.8(109)$ & $53.7(58)$ & $46.3(50)$ \\
\hline Associate's degree & $17.3(91)$ & $60.4(55)$ & $39.6(36)$ \\
\hline Bachelor's degree or higher & $49.3(259)$ & $44.8(116)$ & $55.2(143)$ \\
\hline \multicolumn{4}{|l|}{ Marital status } \\
\hline Single & $16.8(88)$ & $44.3(39)$ & $55.7(49)$ \\
\hline Married, domestic partner, long term & $65.9(346)$ & $49.0(169)$ & $51.0(176)$ \\
\hline Divorced, separated, windowed & $17.1(90)$ & $34.4(31)$ & $65.6(59)$ \\
\hline \multicolumn{4}{|l|}{ VA services eligible } \\
\hline No & $5.5(29)$ & $93.1(27)$ & $6.9(2)$ \\
\hline Yes & $87.6(460)$ & $41.6(191)$ & $58.4(268)$ \\
\hline \multicolumn{4}{|l|}{ Above PCL-5 cutoff } \\
\hline No & $11.2(57)$ & $82.5(47)$ & $17.5(10)$ \\
\hline Yes & $88.8(450)$ & $40.3(181)$ & $59.7(268)$ \\
\hline \multicolumn{4}{|l|}{ Above PHQ-9 cutoff } \\
\hline No & $1.0(5)$ & $60.0(3)$ & $40.0(2)$ \\
\hline Yes & $99.0 \%(509)$ & 45.9 (233) & 54.1 \\
\hline
\end{tabular}

$N B$ numbers may not add up due to missing data 
Table 2 Coefficients and Odds Ratios with 95\% confidence intervals (CI) of the model investigating the association of PTSD symptom severity and depression symptom severity on treatment-seeking

\begin{tabular}{lll}
\hline & B (S.E.) & Adjusted OR (95\% CI) \\
\hline PTSD symptom severity & 0.031 & $1.03(1.02-1.04)^{*}$ \\
Constant & -1.571 & \\
Depression symptom severity & 0.103 & $1.11(1.08-1.14)^{*}$ \\
Constant & -1.999 & \\
\hline
\end{tabular}

PTSD model $-\mathrm{R}^{2}=.056$ (Cox and Snell) .075 (Nagelkerke). Model $X^{2}(1)=25.63 ; p \leq .001$. Depression model $-\mathrm{R}^{2}=.092$ (Cox and Snell) .12 (Nagelkerke). Model $X^{2}(1)=48.92 ; p \leq .001 . * p<.001$

\section{Univariate Analysis of Symptom Severity and Treatment-Seeking}

The mean PCL-5 score among the veterans in the PTSD sample was 63.9 (16.2 SD; 33-100 range). Using the PTSD sample, in a model with 448 cases analyzed, univariate logistic regression analysis indicated that PTSD symptom severity was positively associated with treatment-seeking. The mean PHQ-9 score among the veterans in the depression sample was 21.1 (6.4 SD; 10-36 range). Using the depression sample, in a model with 507 cases analyzed, univariate logistic regression analysis also indicated that depression symptom severity was positively associated with treatment-seeking (Table 2).

\section{Univariate Analysis of Self-efficacy and Treatment-Seeking}

In the sample of veterans reporting the clinical cut-off for PTSD ( $n=450), 440$ answered all of the questions on the general self-efficacy scale with a mean score of 27.7 (5.9 SD; 10-40 range). Using this PTSD sample, univariate logistic regression analysis including a model with 439 cases analyzed, indicated that general self-efficacy has a negative direct association with treatment-seeking.

In the sample of veterans reporting the clinical cut-off for depression $(n=509), 501$ answered all of the questions on the general self-efficacy scale with a mean score of 28.4 (6.02 SD; $10-40$ range). Using the sample of those above the clinical cutoff for depression, a univariate logistic regression analysis, including a model with 500 cases analyzed, indicated that general self-efficacy has a negative direct association with treatment-seeking (Table 3).

\section{Multivariate Analysis of the Effect of Symptom Severity and Self-efficacy on Treatment-Seeking}

\section{PTSD Sample}

To examine hypotheses 1 and 2, multivariate logistic regression analysis was conducted using the PTSD sample. In a
Table 3 Coefficients and Odds Ratios with 95\% confidence intervals (CI) of the association between general self-efficacy and treatmentseeking in samples with those with probable PTSD and those with probable depression

\begin{tabular}{lll}
\hline & B (S.E.) & Adjusted OR (95\% CI) \\
\hline PTSD sample & & \\
General self-efficacy & -.145 & $.87(.83-.90)^{*}$ \\
$\quad$ Constant & 4.481 & \\
Depression sample & & \\
General self-efficacy & -.163 & $.85(.82-.88)^{*}$ \\
$\quad$ Constant & 4.860 & \\
\hline
\end{tabular}

PTSD model- $\mathrm{R}^{2}=.126$ (Cox and Snell) .171 (Nagelkerke). Model $X^{2}(1)=23.93 ; p \leq .01$. Depression model $-\mathrm{R}^{2}=.163$ (Cox and Snell) .218 (Nagelkerke). Model $X^{2}(1)=89.02 ; p \leq .001 . * p<.001$

model with 439 cases analyzed, the multivariate analysis indicated that both PTSD symptom severity (1.03 OR; $1.01-1.0495 \% \mathrm{CI}$ ) and general self-efficacy (0.87 OR; $0.83-0.9195 \% \mathrm{CI}$ ) had a positive main effect on treatmentseeking. Age, gender, and marital status were added to the model as co-variates however, only gender was significant and included in the final analysis. Multivariate logistic regression analysis with 439 cases analyzed, indicated that PTSD symptom severity had a positive main effect on treatment-seeking and self-efficacy had a negative main effect on treatment-seeking, with gender as a covariate indicating that women are more likely to seek treatment (Table 4). These results provide evidence of the acceptance of hypotheses one for those with probable PTSD. However, hypotheses two is only partially supported, as although a direct main effect was found, it was in the direction opposite to predicted.

\section{Depression Sample}

Hypotheses 1 and 2 were also tested using the depression sample. In a model with 482 cases analyzed, multivariate logistic regression analysis indicated that both depression symptom severity (1.07 OR: 1.04-1.11 95\% CI) and general self-efficacy (0.87 OR: $0.83-0.9095 \% \mathrm{CI}$ ) had a positive main effect on treatment-seeking. Age, gender, and marital status were added to the model as covariates and indicated that age and marital status made a significant contribution to the model. Multivariate logistic regression analysis with 499 cases analyzed, indicated that depression symptom severity had a positive main effect on treatment-seeking and self-efficacy had a negative main effect on treatment-seeking with the covariates indicating that those who were older were more likely to seek treatment, and those who were married were less likely to seek treatment compared to those who were single (Table 4). These results support H1. However, H2 was partially supported because even though a direct 
Table 4 Coefficients and Odds Ratios with 95\% CI of a multivariate logistic regression analysis investigating the main effect of PTSD symptom severity and general self-efficacy on treatment-seeking with the inclusion of age and gender as covariates

\begin{tabular}{lll}
\hline & B (S.E.) & Adjusted OR (95\% CI) \\
\hline PTSD symptom severity & .025 & $1.03(1.01-1.04)^{* *}$ \\
General self-efficacy & -.135 & $.87(.84-.91)^{* *}$ \\
Gender & & \\
$\quad$ Male & & \\
Female & .734 & $2.08(1.16-3.73)^{*}$ \\
Constant & 2.527 & \\
Depression symptom severity & .068 & $1.07(1.04-1.11)^{* *}$ \\
General self-efficacy & -.148 & $.86(.83-.90)^{* *}$ \\
Age & .028 & $1.03(1.00-1.05)^{*}$ \\
Marital status & & \\
$\quad$ Single (base) & - & - \\
$\quad$ Married, domestic partner, long & -.680 & $.51(.29-.89)^{*}$ \\
$\quad$ term & & \\
$\quad$ Divorced, separated, windowed & -.249 & $.78(.377-1.62)$ \\
Constant & 2.450 & \\
\hline
\end{tabular}

PTSD model $-\mathrm{R}^{2}=.167$ (Cox and Snell) .226 (Nagelkerke). Model $X^{2}(1)=80.34 ; p \leq .01$. Depression model $-\mathrm{R}^{2}=.208$ (Cox and Snell) .278 (Nagelkerke). Model $X^{2}(1)=116.25 ; p \leq .001$. $* p<0.05$; $* * p<0.001$

main effect was found, it was in the direction opposite to what was predicted.

\section{Is There an Interaction Effect Between Symptom Severity and General Self-efficacy?}

An interaction term was added to the multivariate logistic regression models (excluding the covariates) for both the probable PTSD and depression samples. Results of these analyses indicated that the interaction effects in both samples were not significant (Table 5).

\section{Discussion}

Guided by the Health Belief Model (HBM) (Rosenstock et al. 1988), this study examined the associations of symptom severity and self-efficacy on treatment-seeking among a sample of post $9 / 11$ veterans. The overall prevalence of treatment-seeking $(54.4 \%)$ among this study sample $(n=525)$ is consistent with the prevalence of treatment-seeking found in other studies with similar veteran samples (DeViva et al. 2016; Porcari et al. 2017; Rosen et al. 2011).

Hypothesis 1 tested whether symptom severity had a positive main effect on treatment-seeking and was confirmed for PTSD symptom severity and depression symptom severity. Consistent with previous literature and the HBM (Adler
Table 5 Coefficients and Odds Ratios with 95\% CI of a multivariate logistic regression analysis investigating the interaction effect of PTSD symptom severity and general self-efficacy on treatment-seeking

\begin{tabular}{lcl}
\hline & B (S.E.) & Adjusted OR (95\% CI) \\
\hline PTSD symptom severity & -.036 & $.96(.89-1.04)$ \\
General self-efficacy & -.281 & $.76(.63-.91)^{*}$ \\
PTSD*GSE & .002 & $1.00(1.00-1.01)^{\dagger \dagger}$ \\
$\quad$ Constant & & \\
Depression symptom severity & -.105 & $.90(.75-1.09)$ \\
General self-efficacy & -.273 & $.76(.66-88)^{* *}$ \\
Depression*GSE & .006 & $1.00(1.00-1.01)^{\dagger}$ \\
$\quad$ Constant & 6.849 & \\
\hline
\end{tabular}

PTSD model- $\mathrm{R}^{2}=.160$ (Cox and Snell) .216 (Nagelkerke). Model $X^{2}(1)=76.39 ; p \leq .01$. Depression model $-\mathrm{R}^{2}=.197 \quad(\mathrm{Cox}$ and Snell) .264 (Nagelkerke). Model $X^{2}(1)=109.90 ; p \leq .001 . * p<0.05$; $* * p<0.001 ;{ }^{\dagger} 068 ;{ }^{\dagger \dagger} .112$

et al. 2015; DeViva et al. 2016; Porcari et al. 2017; Rosen et al. 2011), the results from this study indicate that higher depression and PTSD symptoms are associated with an increased likelihood that veterans will seek treatment.

Hypotheses 2 tested whether general self-efficacy was associated with treatment-seeking as per the suggestion of Rosenstock et al. (1988) in terms of the HBM. In both the depression and PTSD samples a main effect was found but in the opposite direction predicted. Rather than increased self-efficacy being associated with an increased likelihood of treatment-seeking, increased self-efficacy was associated with a decreased likelihood of treatment-seeking. This is consistent with the results of a study conducted with a rural general population sample that found that lower selfefficacy was associated with an increased likelihood to seek treatment (Jackson et al. 2007). This association between self-efficacy and treatment-seeking requires further investigation and replication with other veteran and non-veteran populations.

One of the most frequently reported barriers to care found in existing research with veterans (Adler et al. 2015; Keeling et al. 2017; Momen et al. 2012; Sayer et al. 2009; Stecker et al. 2007), and in some civilian studies (Mojtabai et al. 2011), is having a preference for managing their problems on their own. Arguably, self-management requires high self-efficacy and confidence in one's ability to manage the problem independently. Therefore, evidence that high selfefficacy is associated with a decreased likelihood to seek treatment may be due to individuals' confidence in their ability to take care of the problem themselves and a perceived lack of need for external treatment. A preference for managing one's problems on their own, is often considered to be related to the military culture of "soldiering on" and the military ethos of self-reliance (Murphy et al. 2014). It 
is possible that this ethos creates a double edge sword, that while this might be good during military service, it may impact military personnel and veterans' propensity to seek treatment, instead feeling equipped and preferring to manage the problem independently without professional treatment. The association between self-efficacy, a preference for self-management and treatment-seeking requires further investigation.

\section{Limitations}

This study is cross-sectional therefore causation and direction of effect is not guaranteed and the results should be interpreted with this consideration. Self-efficacy was measured using a general measure, rather than a measure specific to self-efficacy of seeking treatment for mental health concerns. Bandura (1982) recommends using measures of selfefficacy specific to the behavior or action under investigation. The lack of use of a treatment-seeking specific measure could have impacted our results. However, a robust measure of treatment-seeking self-efficacy was not available at the time the study was conducted. The odds ratios for the association between PTSD symptoms and depression symptoms, despite being highly significant, are close to 1.00 therefore this result should be interpreted with this in consideration since the strength of association is small.

Otherwise, this study used well validated and robust measures with a large sample of US veterans. The sample demographics are consistent with the veteran population and the prevalence of treatment-seeking was consistent with existing literature, indicating our sample is likely to be representative of the urban veteran population. Studies investigating veterans in rural areas may find different results since rural areas present additional barriers to care. A final strength of this study was that unlike many other studies it did not recruit veterans via VA health services.

\section{Implications and Recommendations}

The results from this research indicate two distinct factors associated with treatment-seeking among US post 9/11 veterans and should be considered when considering ways to improve treatment-seeking for mental health concerns among veterans. Firstly, efforts and interventions directed at improving veterans' ability to recognize their symptoms as treatable and manageable mental health conditions could lead to veterans seeking treatment when symptoms are less severe. As Seal et al. (2009) recommend, early interventions may prevent chronic mental illness.

Secondly, the finding that high self-efficacy is associated with a decreased likelihood to seek treatment, not only draws into question Rosenstock et al.'s (1988) inclusion of self-efficacy in the HBM, but suggests a possible cognitive mechanism important in decisions to seek treatment. A possible explanation for why high self-efficacy likely deters veterans from seeking treatment could be due to the commonly reported barrier of having a preference for managing the problem on their own. The association between self-efficacy and treatment-seeking requires replication in other studies with veteran populations and a possible reconsideration of the inclusion of self-efficacy in the HBM. Moreover, the association between self-efficacy, a preference for self-management, and treatment-seeking requires investigation.

Taken together, these have implications for the overall VA population and access to care. Educational resources made available to the VA population providing psychoeducation about the symptoms of and available treatments for PTSD symptoms and depression symptoms could help increase the propensity to seek treatment. Psychoeducation resources could help increase mental health literacy among the VA population, raise awareness of the experience of symptoms as treatable, and highlight the available support and treatments.

\section{Conclusion}

This study examined the impact of symptom severity and self-efficacy on treatment-seeking for mental health among a US veteran sample. Consistent with previous research and the HBM, symptom severity appears to be a key component influencing treatment-seeking. Although programs designed to alleviate mental health stigma have been provided to military populations, programs targeting symptom identification may be an area of targeted intervention. It appears that selfefficacy is associated with treatment-seeking. Since evidence of this association is limited in the literature, further studies are required to replicate this finding. Moreover, studies to investigate the association between self-efficacy and specific barriers to care are also required. The results of this study provide initial evidence that self-efficacy could be an underlying cognitive mechanism important in decisions to seek- treatment.

Acknowledgements The authors would like to thank the USC Suzanne Dworak-Peck School of Social Work Research Council for providing the funding award for this study. The authors wish to thank the many veterans who took the time to participate in this study.

\section{Compliance with Ethical Standards}

Conflict of interest The funding for this study was provided by the Research Council of the school where all authors were either currently employed or a student. The authors declare that they have no conflict of interest. 
Open Access This article is licensed under a Creative Commons Attribution 4.0 International License, which permits use, sharing, adaptation, distribution and reproduction in any medium or format, as long as you give appropriate credit to the original author(s) and the source, provide a link to the Creative Commons licence, and indicate if changes were made. The images or other third party material in this article are included in the article's Creative Commons licence, unless indicated otherwise in a credit line to the material. If material is not included in the article's Creative Commons licence and your intended use is not permitted by statutory regulation or exceeds the permitted use, you will need to obtain permission directly from the copyright holder. To view a copy of this licence, visit http://creativecommons.org/licenses/by/4.0/.

\section{References}

Adler, A. B., Britt, T. W., Riviere, L. A., Kim, P. Y., \& Thomas, J. L. (2015). Longitudinal determinants of mental health treatmentseeking by US soldiers. British Journal of Psychiatry, 207(4), 346-350. https://doi.org/10.1192/bjp.bp.114.146506.

Andersson, L. M., Moore, C. D., Hensing, G., Krantz, G., \& StalandNyman, C. (2014). General self-efficacy and its relationship to self-reported mental illness and barriers to care: A general population study. Community Mental Health Journal, 50(6), 721-728. https://doi.org/10.1007/s10597-014-9722-y.

Bandura, A. (1982). Self-efficacy mechanism in human agency. American Psychologist, 37(2), 122-147. https://doi. org/10.1037/0003-066X.37.2.122.

Bovin, M. J., Marx, B. P., Weathers, F. W., Gallagher, M. W., Rodriguez, P., Schnurr, P. P., et al. (2016). Psychometric properties of the PTSD checklist for diagnostic and statistical manual of mental disorders-fifth edition (PCL-5) in veterans. Psychological Assessment, 28(11), 1379-1391. https://doi.org/10.1037/pas0000254.

Clement, S., Schauman, O., Graham, T., Maggioni, F., Evans-Lacko, S., Bezborodovs, N., ... Thornicroft, G (2014). What is the impact of mental health-related stigma on help-seeking? A systematic review of quantitative and qualitative studies. Psychological Medicine, 45(1), 11-27. https://doi.org/10.1017/S0033291714000129.

DeViva, J. C., Sheerin, C. M., Southwick, S. M., Roy, A. M., Pietrzak, R. H., \& Harpaz-Rotem, I. (2016). Correlates of VA mental health treatment utilization among OEF/OIF/OND veterans: Resilience, stigma, social support, personality, and beliefs about treatment. Psychological Trauma, 8(3), 310-318. https://doi.org/10.1037/ tra0000075.

Henderson, C., Evans-Lacko, S., \& Thornicroft, G. (2013). Mental illness stigma, help seeking, and public health programs. American Journal of Public Health, 103(5), 777-780. https://doi. org/10.2105/AJPH.2012.301056.

Hines, L. A., Goodwin, L., Jones, M., Hull, L., Wessely, S., Fear, N. T., Rona, R. J. (2014). Factors affecting help seeking for mental health problems after deployment to Iraq and Afghanistan. Psychiatric Services (Washington, D. C.), 65(1), 98-105. https://doi. org/10.1176/appi.ps.004972012.

Hoge, C. W., Castro, C. A., Messer, S. C., McGurk, D., Cotting, D. I., \& Koffman, R. L. (2004). Combat duty in Iraq and Afghanistan, mental health problems, and barriers to care. New England Journal of Medicine, 351(1), 13-22. https://doi.org/10.1056/NEJMo a040603.

Jackson, H., Judd, F., Komiti, A., Fraser, C., Murray, G., Robins, G., ... Waring, A. (2007). Mental health problems in rural contexts: What are the barriers to seeking help from professional providers? Australian Psychologist, 42(2), 147-160. https://doi. org/10.1080/00050060701299532.

Keeling, M., Bull, S., Thandi, G., Brooks, S., \& Greenberg, N. (2017). U.K. army medical and unit welfare officers' perceptions of mental health stigma and its impact on army personnel's mental health help seeking. Military Behavioral Health, 5(3), 245-253. https://doi.org/10.1080/21635781.2017.1310682.

Kroenke, K., Spitzer, R. L., \& Williams, J. B. W. (2001). The PHQ-9: Validity of a brief depression severity measure. Journal of General Internal Medicine, 16(9), 606-613. https://doi.org/10.104 6/j.1525-1497.2001.016009606.x.

Mojtabai, R., Olfson, M., Sampson, N. A., Jin, R., Druss, B., Wang, P. S., ... Kessler, R. C. (2011). Barriers to mental health treatment: Results from the National Comorbidity Survey Replication. Psychological Medicine, 41(8), 1751-1761. https://doi.org/10.1017/ s0033291710002291.

Momen, N., Strychacz, C. P., \& Viirre, E. (2012). Perceived stigma and barriers to mental health care in Marines attending the Combat Operational Stress Control program. Military Medicine, 177(10), 1143-1148.

Murphy, D., Hunt, E., Luzon, O., \& Greenberg, N. (2014). Exploring positive pathways to care for members of the UK Armed Forces receiving treatment for PTSD: A qualitative study. European Journal of Psychotraumatology. https://doi.org/10.3402/ejpt. v3405.21759.

Ouimette, P., Vogt, D., Wade, M., Tirone, V., Greenbaum, M. A., Kimerling, R., ... Rosen, C. S. (2011). Perceived barriers to care among veterans health administration patients with posttraumatic stress disorder. Psychological Services, 8(3), 212-223. https://doi. org/10.1037/a0024360.

Porcari, C., Koch, E. I., Hoodin, F., Ellison, G., McSweeney, L., \& Rauch, S. A. M. (2017). Predictors of help-seeking intentions in operation enduring freedom and operation iraqi freedom veterans and service members. Military Medicine, 182(5), e1640-e1647. https://doi.org/10.7205/MILMED-D-16-00105.

Rosen, C. S., Greenbaum, M. A., Fitt, J. E., Laffaye, C., Norris, V. A., \& Kimerling, R. (2011). Stigma, help-seeking attitudes, and use of psychotherapy in veterans with diagnoses of posttraumatic stress disorder. The Journal of Nervous and Mental Disease, 199(11), 879-885. https://doi.org/10.1097/NMD.0b013e3182349ea5.

Rosenstock, I. M., Strecher, V. J., \& Becker, M. H. (1988). Social learning theory and the Health Belief Model. Health Education Quarterly, 15(2), 175-183.

Sayer, N. A., Friedemann-Sanchez, G., Spoont, M., Murdoch, M., Parker, L. E., Chiros, C., et al. (2009). A qualitative study of determinants of PTSD treatment initiation in veterans. Psychiatry, 72(3), 238-255. https://doi.org/10.1521/psyc.2009.72.3.238.

Schwarzer, R., \& Jerusalem, M. (1995). The General Self-Efficacy Scale (GSE). In J. Weinman, S. Wright, \& M. Johnston (Eds.), Measures in health psychology: A user's portfolio. Causal and control beliefs (pp. 35-37). Windsor: NFER-Nelson.

Seal, K. H., Metzler, T. J., Gima, K. S., Bertenthal, D., Maguen, S., \& Marmar, C. R. (2009). Trends and risk factors for mental health diagnoses among Iraq and Afghanistan veterans using Department of Veterans Affairs health care, 2002-2008. American Journal of Public Health, 99(9), 1651-1658. https://doi.org/10.2105/ ajph.2008.150284.

Sharp, M. L., Fear, N. T., Rona, R. J., Wessely, S., Greenberg, N., Jones, N., Goodwin, L. (2015). Stigma as a barrier to seeking health care among military personnel with mental health problems. Epidemiologic Reviews, 37, 144-162. https://doi. org/10.1093/epirev/mxu012.

Stecker, T., Fortney, J. C., Hamilton, F., \& Ajzen, I. (2007). An assessment of beliefs about mental health care among veterans who served in Iraq. Psychiatric Services (Washington, D. C.), 58(10), 1358-1361. https://doi.org/10.1176/ps.2007.58.10.1358.

Thomas, J. L., Wilk, J. E., Riviere, L. A., McGurk, D., Castro, C. A., \& Hoge, C. W. (2010). Prevalence of mental health problems and functional impairment among active component and National Guard soldiers 3 and 12 months following combat in 
Iraq. Archives of General Psychiatry, 67(6), 614-623. https://doi. org/10.1001/archgenpsychiatry.2010.54.

Weathers, F. W., Litz, B. T., Keane, T. M., Palmieri, P. A., Marx, B. P., \& Schnurr, P. P. (2013). The PTSD checklist for DSM-5 (PCL-5). Boston: National Center For PTSD.
Publisher's Note Springer Nature remains neutral with regard to jurisdictional claims in published maps and institutional affiliations. 